\title{
Reconhecimento, justiça e a questão da autonomia: desafios para uma teoria social normativa
}

\author{
Emil Albert Sobottka' \\ Thais Marques de Santo ${ }^{2}$
}

\section{Resumo}

O conhecimento científico em geral, e a teoria social de modo particular, progridem com debates públicos. O debate que Nancy Fraser e Axel Honneth travaram há duas décadas e meia contribuiu para explicitar melhor, no contexto da Teoria Crítica, questões relacionadas ao reconhecimento, à justiça distributiva e também à autonomia dos indivíduos em um cenário em que novos movimentos sociais e novos temas contribuíram para diversificar as lutas sociais. O presente texto rememora brevemente a mudança no cenário, delineia em largos traços o surgimento da proposta de uma teoria do reconhecimento feita por Axel Honneth, para então abordar alguns dos principais aprendizados que aquele debate trouxe, bem como aponta contribuições de Fraser para o campo da Teoria Crítica. Ele se encerra com uma reflexão sobre algumas implicações do debate que poderiam se tornar produtivas em nosso contexto.

Palavras-chave: Reconhecimento. Justiça. Autonomia. Teoria Crítica.

\section{Novos cenários das lutas sociais contemporâneas}

Com a proliferação de movimentos sociais na segunda metade do Século $\mathrm{XX}$, as lutas sociais se diversificaram, tornaram-se mais complexas, $\mathrm{e}$

I Doutor em Sociologia e Ciência Politica pela Westfälische Wilhelms-Universität (WWU) Münster, Alemanha, e professor no Programa de Pós-Graduação em Ciências Sociais na Pontifícia Universidade Católica do Rio Grande do Sul (PUC-RS) em Porto Alegre/RS, Brasil. E-mail: sobottka@pucrs.br; Orcid: http://orcid.org/00000001-8615-7305; endereço postal: Av. Ipiranga, 6681, 90619-900 Porto Alegre/RS, Brasil.

2 Mestre e doutoranda no Programa de Pós-Graduação em Ciências Sociais na Pontifícia Universidade Católica do Rio Grande do Sul (PUC-RS) em Porto Alegre/RS, Brasil.E-mail: thais.santo@acad.pucrs.br; Orcid: http:// orcid.org/0000-000 I-6/49-9464.

(c) $)_{\text {EY }}$
Direito autoral e licença de uso: Este artigo está licenciado sob uma Licença Creative Commons. Com essa licença você pode compartilhar, adaptar, para qualquer fim, desde que atribua a autoria da obra, forneça um link para a licença, e indicar se foram feitas alterações. 
colocaram a teoria social diante de novos desafios. Para uma teoria social crítica, que não se contenta em descrever os fenômenos sociais, mas que busca conectar diagnósticos de época com uma avaliação fundada em teoria social de cunho normativo, a elucidação destas bases normativas tornou-se uma exigência central. Enquanto outrora ainda havia sido possível assumir com certa naturalidade o pressuposto advindo da tradição marxista, de que o capitalismo seria superado sob o impulso das lutas do proletariado como o sujeito privilegiado da transformação social (SOBOTTKA, 2008), o novo cenário desfez essa esperança. Ele não apenas revelou que a confiança em uma evolução histórica que necessariamente levaria à superação do capitalismo era equívoca e que o ímpeto revolucionário do proletariado havia enfraquecido, mas trouxe à tona novos sujeitos que colocaram novos temas no centro das lutas sociais.

Enquanto as antigas lutas sociais estavam centradas na questão da distribuição mais igualitária da riqueza socialmente produzida e tinham como estratégia mudanças na relação de poder, os novos movimentos sociais incluíram a dimensão cultural e o fortalecimento identitário em suas lutas (RASCHKE, 1994), dando prioridade à pluralidade e à especificidade distintiva de grupo (EISENSTADT et al., 2013; SANTOS; BARREIRA; BAUMGARTEN, 2003). Ao mesmo tempo em que a constituição de grupos de pesquisa e a multiplicaçáo de eventos e de literatura acadêmica voltados aos novos movimentos sociais indicam a importância por eles adquirida, não faltaram vozes que alertaram para os riscos do entusiasmo com as possíveis ciladas por trás da valorizaçáo excessiva da diferença (PIERUCCI, 1990).

No contexto da Teoria Crítica, a discussão centrou-se fortemente em torno do reconhecimento, e envolveu diferentes interlocutores com suas controvérsias específicas. Uma dessas controvérsias girou ao redor da possibilidade de governos definirem políticas de reconhecimento e preservação de identidades culturais específicas em estados democráticos de direito. Expoentes da controvérsia foram Charles Taylor (1995) e Jürgen Habermas (2002). Outra discussão foi desencadeada por Nancy Fraser $(1997)^{3}$ ao questionar a abordagem proposta por Axel Honneth em sua teoria do reconhecimento.

3 Ver capítulo I. 
Ela está no foco do presente artigo. Os textos centrais foram publicados pelos dois autores em uma obra conjunta (FRASER; HONNETH, 2006).

Ponto de partida foi a tese de Fraser, segundo a qual no início dos anos 1990 se haveria adentrado em um período pós-socialista, e que este se caracterizaria, dentre outros, por um deslocamento na gramática das reivindicações políticas. Segundo a autora, “[...] reivindicaçôes de reconhecimento da diferença de grupos se tornaram intensamente proeminentes recentemente, por vezes eclipsando reivindicaçóes por igualdade social" (FRASER, 1997, p. 2). A transformaçáo mais profunda que esta autora constata teria ocorrido na forma como a justiça é concebida no imaginário político: "Muitos atores parecem estar se afastando de um imaginário político socialista, no qual o problema central da justiça é a redistribuição, para um imaginário político 'pós-socialista', no qual o problema central da justiça é o reconhecimento" (FRASER, 1997, p. 2). Com esse deslocamento, para muitos dos mais importantes movimentos sociais a identidade como classe que defende seus interesses e combate a exploração para ganhar redistribuição teria sido substituída por uma defesa da identidade de grupos ou comunidades combatendo a dominaçáo cultural e buscando o reconhecimento. Para a autora, isso representaria uma ideologia pós-socialista.

Com isso estava colocada uma questão, que Christopher Zurn (2003, p. 519) desdobrou em uma sequência de perguntas:

Como devemos entender [...] o surgimento de demandas por reconhecimento social e político de identidades distintivas de grupo? [...] Tais lutas baseadas na identidade promovem a justiça social em geral dentro de uma sociedade ou elas podem depreciar os ideais igualitários e universalistas ao tender para novas formas de sectarismo? E como uma teoria social orientada por uma intenção emancipatória deve compreender e avaliar esses novos movimentos sociais voltados ao reconhecimento, sem ignorar os problemas mais tradicionais da desigualdade econômica que permanecem conosco?

Com seu questionamento, em especial com a pergunta sobre como uma teoria social orientada por uma intenção emancipatória deve compreender e avaliar o novo cenário das lutas sociais, Zurn (2003) explicita a dimensão central do debate entre Fraser e Honneth que será tratada aqui. Para tanto, o artigo inicia com uma breve descrição da trajetória de 
Honneth que o levou a desenvolver sua proposta de uma teoria do reconhecimento, para entáo acompanhar a crítica e contraproposta de Fraser e as reaçôes de Honneth a elas. $\mathrm{O}$ texto se encerra com uma reflexão sobre algumas implicaçóes que o debate teve na teoria social, e como poderiam se tornar produtivas em nosso contexto.

\section{Intuições que contribuíram para o desenvolvimento da teoria do reconhecimento}

Axel Honneth desenvolve sua contribuição à teoria social ao mesclar um forte ancoramento na tradição teórica da filosofia e da teoria crítica, especialmente em Hegel, com certo experimentalismo teórico. Ou seja: detecta lacunas na teoria social que ele quer preencher, procura por uma intuição que lhe pareça promissora e vai então aos teóricos mais clássicos (em especial Hegel, mas também Dewey, Durkheim, entre outros), e exercita sua intuição para verificar em que medida ela se sustenta como contribuição para superar a deficiência anteriormente diagnosticada.

A primeira grande lacuna apresentada por Honneth, e que constituiu o impulso inicial para o seu próprio projeto de uma teoria social, foi constatada na crítica a Habermas. Ele a desenvolve no livro Crítica ao po$\operatorname{der}(\mathrm{HONNETH}, 2000)$. Para ele, o conceito bidimensional de sociedade de Habermas, em sua teoria da ação comunicativa (HABERMAS, 1988a, 1988b; PINZANI, 2007), excluiria da análise teórica e, portanto, da crítica, as questóes de poder e conflito da esfera de reproduçáo material da sociedade. Ao considerar os âmbitos econômico e político-administrativo da sociedade como subsistemas que se regem através de media específicos em semelhança ao que Niklas Luhmann (1996) concebeu em sua teoria dos sistemas, Habermas teria negligenciado uma esfera considerada por Honneth como absolutamente vital para a teoria social. Esta exclusão está relacionada à separação entre trabalho e interação, entre uma racionalização técnico-instrumental e outra prático-moral, que Habermas assumiu na década de 1960 (HABERMAS, 2003) e que influenciou toda a arquitetura de sua teoria posterior. Aos olhos de Honneth, porém, a tese da autorregulação e a consequente marginalidade da economia e da área político-administrativa seriam injustificadas, porquanto também nelas ocorreriam lutas sociais e relaçóes de poder. Por 
isso, dentre outros, ele recorrerá inicialmente a Foucault para recuperar esta dimensão considerada fundamental na teoria social. Dali surgirá, gradativamente, a proposição de uma luta por reconhecimento. Será uma construção teórica gradativa, composta por vários passos até chegar ao que hoje se conhece como sua teoria do reconhecimento. Recordaremos, a seguir, a intuição que subjaz aos principais passos da construção teórica.

Uma primeira intuição está relacionada à constatação de uma clivagem entre classes sociais, que dificulta a reação das classes subalternas e, assim, perpetua sua dominação. Embora tenha sido membro do Partido SocialDemocrata e mesmo participado por um tempo em um "pequeno grupo socialista”, Honneth diz em uma entrevista nunca "ter acreditado na revoluçáo proletária” (MARCELO, 2013). Mas ele teria observado como os trabalhadores das minas de carvão em sua região natal se percebiam desconfortáveis com sua posição social. Ainda que não fique claro como se deu o trânsito destas observaçóes cotidianas para uma exposição sistematicamente articulada sobre a dominação de classe, em um vocabulário com fortes influências de Marx, Honneth assumiu esta linguagem em uma palestra proferida em Dubrovnic, em 1982 (HONNETH, 2007)4 Dando continuidade à crítica a Habermas, já mencionada, Honneth então se volta contra o que ele descreve como pretensão habermasiana de fundamentar as reivindicaçóes normativas da teoria crítica em uma ética procedimental do discurso, ignorando "[...] todas as formas de crítica social existentes não reconhecidas pela esfera pública politicamente hegemônica” (HONNETH, 2007, p. 82).

Segundo Honneth (2007), os grupos excluídos, como "classes subalternas" teriam muita dificuldade em articular sua resistência e sua luta pela superação da situação de injustiça. De um lado, porque estão fortemente individualizadas e, por conseguinte, suas forças estão dispersas; de outro, porque foram, por assim dizer, "des-simbolizadas". Ou seja: esses grupos não têm (mais) uma capacidade de abstração suficiente que lhes permita articular em termos razoavelmente abstratos projetos alternativos de organização social. Mas isso não significa que não tivessem concepçóes normativas de valor nem que deixassem de perceber sua situação como injusta.

4 Mais informações, no capítulo 4. 
As classes subalternas deteriam, sim, consciência de injustiça que teria como base critérios implícitos de desaprovação moral, mas elas estão sujeitas a um eficaz conjunto de mecanismos de controle que limita a articulação de sua consciência de injustiça, mantendo assim a dominação capitalista. A sugestão de Honneth, por conseguinte, será de que uma teoria crítica necessitaria desenvolver estudos empíricos para detectar tanto as percepçóes de injustiça quanto os critérios normativos implícitos destas classes, que náo estariam presentes articuladamente na esfera pública. Em suas palavras: "[...] eu gostaria de propor a tese de que uma análise crítica da sociedade deve ver como sua tarefa hoje a identificação de conflitos morais ligados à estrutura de classe social que estão escondidos por trás da fachada de integração do capitalismo tardio" (HONNETH, 2007, p. 90).

A segunda intuição forte no desenvolvimento da teoria de Honneth girou em torno da questão da luta. A noção de luta que Hegel emprega inicialmente na criminologia e depois na relação entre senhor e escravo influenciará significativamente a parte inicial de Luta por reconhecimento (HONNETH, 2003). Mas neste livro entram também as questóes da identidade, da formação do sujeito com uma razoável autonomia. Honneth desenvolve nele a tese de que na modernidade teria havido uma pluralização da vida. Não é algo exatamente novo: Weber já tinha, por exemplo, desenvolvido esta questão em Classe, estamento e partido e em Rejeiçóes religiosas do mundo e suas dimensóes (WEBER, 1982) 5 . Honneth, no entanto, desenvolve sua tese das três dimensóes do reconhecimento (amor, direito e solidariedade), ao passo que em Weber o foco estava nas dimensóes da distribuição do poder (em Classe, estamento e partido) e nas diferentes formas que a racionalização assume em distintas esferas da vida moderna (em Rejeiçóes religiosas do mundo e suas direçóes). Para Honneth, o reconhecimento seria fundamental em cada esfera para que o indivíduo possa manter em cada uma um tipo específico de relaçôes práticas positivas ou saudáveis consigo mesmo. Essa seria a base da formação da identidade do indivíduo, livre e autônomo. Autores como Winnecott e Mead ganham grande relevância nesta etapa, enquanto Foucault perde destaque. A influência de Marx praticamente desaparece da teoria de Honneth desde o início dos

5 Conferir capítulos 7 e 13. 
anos 1990. Hegel foi e segue sendo a referência central de Honneth, embora seja lido em perspectivas diferentes.

\section{Fraser e a pergunta pela redistribuição na teoria social}

É neste estágio do desenvolvimento da teoria do reconhecimento por Honneth que Nancy Fraser entra no debate. Ela começou basicamente em 1995 a desenvolver uma proposta alternativa de teoria que não identifica como ligada ao reconhecimento, mas designa como sendo uma teoria bifocal de justiça (FRASER, 19976; FRASER; HONNETH, 20037). Esta proposta toma como seu foco tanto a dimensão cultural como a economia política, e inclui necessariamente duas dimensôes claramente distintas: reconhecimento e redistribuição. Sua crítica a Honneth (e Taylor) é que eles teriam deixado de lado as questóes relativas à justiça distributiva, à reprodução material da vida e às lutas dentro dela, para se concentrar em questóes relativas à esfera identitário-cultural. Conforme argumenta, para estes autores reconhecimento é uma questão de realização pessoal, enquanto em sua abordagem, reconhecimento é uma questão de justiça (MATTOS, 2004).

Em sua proposta, Fraser realça a importância da relação entre a negação de reconhecimento ou o desreconhecimento (misrecognition) e a má distribuição de bens materiais (renda e oportunidades), com vistas a subsidiar a atuação prático-política. Segundo a interpretação de Zurn (2003), ela separa essas duas dimensóes de forma até mais rígida que o havia feito Habermas. E não deixa de ser irônica sua crítica a Honneth, porquanto um ponto de partida de sua teoria é justamente a constatação de que as lutas sociais da esfera da reprodução material estariam subvalorizadas na teoria de Habermas.

Um dos argumentos centrais para o modelo bifocal de Fraser é que há injustiças distributivas que não têm base em padróes culturais de valoração, mas que dependem unicamente da lógica do mercado capitalista (FRASER, 2006a). Que haveria, pois, uma separação razoavelmente forte

\footnotetext{
Ver capítulo I.

7 Mais detalhes, nos capítulos I e 3 .
} 
entre ambas. Esta separação é evidenciada por Fraser a partir do diagnóstico de que o pós-fordismo, o pós-comunismo e a globalização deslocaram o foco das lutas sociais da redistribuição para o reconhecimento. Assim, os interesses identitários teriam suplantado os interesses de classe, pois os movimentos têm atuado a partir da lógica de que para defender as diferenças identitárias é preciso abrir mão da igualdade material e de direitos.

Fraser categoriza os movimentos sociais a partir da natureza de suas demandas, destacando as classes sociais exploradas que reivindicam redistribuiçáo, e as sexualidades depreciadas onde a demanda é por reconhecimento. Desenvolve, então, a sua teoria bidimensional apresentando movimentos sociais que devem abarcar as duas classes de demandas (sem que uma suplante a outra): os movimentos de gênero e raça.

O diagnóstico da polarização no campo dos movimentos sociais é elucidativo do contexto contemporâneo. No entanto, ao buscar fundamentar teoricamente essa observação, embora coerente com seu entendimento de que a crítica deve emanar dos movimentos sociais, Fraser apresenta uma proposta fundamentada empiricamente, mas com dificuldades de sustentação teórica.

O modelo de status adotado por Fraser tem uma vantagem na abordagem da identidade feita por alguns autores, inclusive em certa medida à forma como Honneth a abordou em Luta por reconhecimento: ela é vista em perspectivasociológica, como identidade do grupo. Negação de reconhecimento surge como relevante para a identidade na medida em que estruturas sociais negam sistematicamente oportunidades para igual participação na vida social aos membros de grupos colocados à margem. Negação de reconhecimento não é mais vista como restrita a relaçóes interpessoais ou episódica, mas como institucionalmente ancorada, como mecanismo social que leva à subordinação sistemática coletiva. Uma forma legítima de luta social por reconhecimento nestas condições, por conseguinte, será a luta pela mudança dos padróes institucionalizados de valores culturais que menosprezam outras pessoas ou grupos. Ou seja, uma luta que tenha como foco a desconstrução dos elementos gerativos da injustiça. Nos termos de Fraser (1997), é necessária a adoção de remédios transformativos, que irão agir na garantia dos direitos materiais e de status, em oposição aos remédios 
afirmativos que, ao atuarem sobre os problemas da ordem da redistribuição, negam a diferença e, em contraponto, ao buscarem reconhecimento, as diferenças são reforçadas. Ou seja, para a autora urge a tarefa de desinstitucionalizar padróes de valoração cultural que impedem a paridade de participação e sua substituição por padróes que a promovam.

Em meio ao debate com Honneth, Fraser insere a paridade de participação como o elemento central da sua teoria da justiça. Ela pressupóe como dada sua aceitação como um valor normativo. Em suas palavras: "O centro normativo da minha concepção é a noçáo de paridade de participação. De acordo com essa norma, a justiça requer arranjos sociais que permitam a todos os membros (adultos) da sociedade interagir uns com os outros como parceiros" (FRASER, 2007, p. 118).

Fraser constata que sua teoria apresenta uma circularidade (não viciosa), onde a paridade de participação é normativa em contextos de deliberação democrática equitativa; e é apenas a possibilidade de participação igualitária em processos democráticos que produzirá a distribuição justa e o reconhecimento recíproco. Estas, por sua vez, são precondições para a paridade participativa. Para a autora, a circularidade somente poderá ser rompida na prática, com a "modificação da realidade social" (FRASER, 2006a, p. 49).

E a autora continua desdobrando as duas condiçôes necessárias para essa participação qualificada, que estão intimamente vinculadas à sua teoria bifocal - ou bidimensional: "Em primeiro lugar, a distribuição dos recursos materiais deve dar-se de modo que assegure a independência e a 'voz' de todos os participantes" (FRASER, 2006a, p. 42). Essa condição diz respeito à desigualdade material e à dependência econômica, e é por ela designada de condiçâo objetiva. Em uma sociedade capitalista, por exemplo, que é estruturada por princípio sobre uma igualdade puramente abstrata perante o marco legal, que é indiferente frente a uma desigualdade material nas condiçóes concretas de vida (FLICKINGER, 2003), e onde a esmagadora maioria das pessoas economicamente ativas está inserida em relaçóes de trabalho dependente, via de regra por assalariamento, essa dimensão da distribuição de recursos precisa ser nuançada. Por isso, Fraser esclarece que, em sua visão, com essa condição estão “[...] excluídos os acordos sociais 
que institucionalizam a privação, a exploração e as grandes disparidades de riqueza, renda e tempo livre, negando, assim, a algumas pessoas os meios e as oportunidades de interagir com outros como parceiros" (FRASER, 2006a, p. 42). Não está, pois, advogando igualdade nas condiçóes materiais, mas diferenças razoáveis, sem detalhar o que seria razoável. Como bem mostraram Chris Armstrong e Simon Thompson (2009), Fraser reconhece a dificuldade com uma definição mais precisa da igualdade e da ordem de status pertinente, mas a subestima.

A segunda condição necessária para a participação qualificada, segundo Fraser (2006a, p. 42), “[...] requer que os padróes institucionalizados de valor cultural expressem igual respeito a todos os participantes e assegurem igual oportunidade para alcançar estima social”. Fraser a designa como condição intersubjetiva de paridade participativa. Também nessa condição a ênfase da autora está na institucionalização negativa e distorcedora. Mas, enquanto na condição objetiva para a participação paritária a autora se voltava às questóes da economia política, agora ela enfoca a dimensão cultural e as formas em que sistematicamente pessoas são desvalorizadas por atributos coletivos. Em suas palavras: a valoração cultural necessária para uma participação paritária exclui “[...] normas institucionalizadas que sistematicamente depreciam algumas categorias de pessoas e as características associadas a elas". Ela concretiza essa distorção como sendo, por exemplo, "[...] padrôes institucionalizados de valores que negam a algumas pessoas o status de participantes plenos na interaçáo, seja adscrevendo-lhes uma 'diferença' excessiva, seja não reconhecendo suas características distintivas" (FRASER, 2006a, p. 43).

Há dois pressupostos na formulação de paridade participativa feita por Fraser que precisam ser problematizados. O primeiro deles é tomar como dada a participaçáo enquanto um valor, enquanto ferramenta para a produção de uma sociedade democrática, desconsiderando a forma constantemente adotada da participação enquanto uma estratégia de governo, utilizada como instrumento de marketing sem nenhum interesse em repartir o poder, como o caso de regimes ditatoriais ou interesses orientados pelo mercado (SOBOTTKA; STRECK, 2014). O segundo pressuposto de Fraser a ser questionado é o de que por meio da participaçáo paritária 
serão produzidos, necessariamente, conteúdos emancipatórios e ocorrerá a superação das injustiças de todas as ordens, enquanto percebemos - mesmo em uma democracia voltada para a representação institucional, como a brasileira - uma parcela significativa dos eleitores orientada pelo desejo de restauração de restriçóes institucionais a direitos individuais.

A questão mais complexa, para a qual Fraser não tem resposta em sua abordagem é: por que a paridade participativa seria normativamente justificada/necessária? Ela tem uma série de razoáveis argumentos pragmáticos. Mas se a teoria crítica quer ser uma teoria normativamente fundada, Fraser tem um défice teórico central em sua proposta (ROBEYNS, 2003).

Seu modelo de Teoria Crítica está assentado na premissa de que "[...] esta tradição deve buscar na organização empiricamente observável dos movimentos sociais a fonte de experiências que permita ao teórico crítico visualizar na opressão de determinadas características uma patologia a ser superada" (SOUZA, 2013, p. 4). Na proposição de Fraser de "reconhecimento sem ética" ou de "crítica social sem filosofia", os critérios para a crítica - extraídos dos próprios movimentos sociais - são insuficientes na garantia da crítica e de padróes éticos e de boa vida que sejam universalizáveis.

Em sua resposta a Fraser, Honneth (2006, p. 107) afirma que o objetivo central de sua teoria do reconhecimento é interpretar os conflitos de distribuição de acordo com a gramática moral de uma luta por reconhecimento. Sendo o conflito social produto do sentimento de injustiça partilhado por atores sociais que tiveram suas expectativas morais violadas, a luta por reconhecimento pode ser desencadeada por desrespeito de qualquer ordem: material, cultural, jurídica. Desse modo, fica evidente que "[...] ao reconstruir os conflitos sociais como lutas por reconhecimento, Honneth não estaria, então, excluindo ou negando a importância das reivindicaçóes por redistribuiçãa, mas reconstruindo-as de uma perspectiva normativa” (BRESSIANI, 2010, p. 18).

Em diferenciação a Habermas, Honneth (2006, p. 112) defende que “[...] a distribuição material tem lugar de acordo com princípios de valor [...] que têm a ver com o respeito, com a estima social dos membros da sociedade". Para Honneth, portanto, as lutas distributivas são (também) 
lutas simbólicas a respeito da legitimidade dos dispositivos socioculturais que determinam o valor de atividades, atributos e contribuiçóes sociais das pessoas. Este autor argumenta que, mesmo se atentarmos para movimentos em épocas passadas - trabalhadores do Século XIX, grupos de mulheres emancipadas no início do Século XX e afro-americanos das grandes cidades dos Estados Unidos na década de 1920 - encontraremos em seus protestos a articulação de registros de humilhação e desrespeito social (HONNETH, 2006, p. 107-108).

\section{Avanços na teoria social}

Em textos mais recentes, Honneth incluiu reiteradamente em sua abordagem as dimensóes que Fraser havia designado de objetiva e intersubjetiva. Ele não as coloca no mesmo contexto como Fraser, de uma paridade participativa, mas na necessária distinção entre reconhecimento verdadeiro e reconhecimento como ideologia (HONNETH, 2004). Segundo o autor, nas sociedades atuais têm havido formas distorcidas de reconhecimento, como na promoção do empreendedorismo, que racionalizam através de supostas virtudes a exploração de sobretrabalho. Interessante é, sobretudo, que a dimensão material do reconhecimento é colocada por Honneth na forma de direitos sociais como condição da liberdade moral, a dimensão em que está sendo tratada a capacidade reflexiva do indivíduo $(\text { HONNETH, 2015) })^{8}$.

O contra-argumento de Fraser para o argumento de Honneth, de que tanto as lutas que enfatizam o reconhecimento como aquelas que enfatizam a redistribuição poderiam ser interpretadas no marco de sua teoria do reconhecimento, é o da irredutibilidade dos conflitos econômicos a conflitos simbólicos. A autora indica que nas sociedades há mais de um tipo de integração social e que, nas sociedades capitalistas, os elementos simbólicos produzem ideologias de valorização ou desvalorização de contribuiçôes dadas à comunidade, do que se considera trabalho, de distribuição de ocupaçôes etc. Mas a autora entende que também há fatores político-econômicos que influenciam nos salários: "[...] a oferta e a demanda de distintos tipos

8 Conforme cap. B2. 
de trabalho; o equilíbrio de poder entre trabalho e capital; o rigor das regulamentaçôes sociais, incluindo o salário mínimo; a disponibilidade e o custo das tecnologias de melhoria da produtividade [...]", entre outros fatores, que náo seriam da esfera cultural, mas do âmbito da economia política (FRASER, 2006b, p. 161). Há uma boa plausibilidade na forma como ela constrói seu argumento e os exemplos que apresenta neste contexto.

A mudança de ênfase feita por Honneth, deixando de lado a dimensão individual-identitária para acolher em seu vocabulário esferas sociais do reconhecimento foi, sem dúvida, uma consequência positiva do debate com Fraser. Além disso, em Luta por reconhecimento o terceiro padrão de reconhecimento intersubjetivo era definido como solidariedade e colocado como expressão de uma comunidade de valores. Já no primeiro texto em resposta a Fraser, junto com a substituição da designação de padróes intersubjetivos de reconhecimento para esferas sociais de reconhecimento, Honneth tematiza na terceira esfera a valorização que a contribuição social de cada um recebe na coletividade. Ele designará essa terceira esfera de Leistung, termo que, em português, por falta de uma expressão precisa, se pode traduzir como "contribuição à sociedade". Esse novo enfoque abre para ele a possibilidade de explicitar a necessidade de que, para além do trabalho formal, outras atividades importantes para a sociedade possam ser foco de lutas por reconhecimento. Além disso, como nem toda contribuição dada à sociedade receberá exatamente a mesma valorização, a nova formulação permite que Honneth conjugue, em sua abordagem, a dimensão igualitária associada ao status como cidadáo, da segunda esfera, com a aceitaçáo pragmática de algum grau de desigualdade na distribuição da riqueza socialmente produzida, relacionada à estima recebida na terceira esfera.

Contra a linha argumentativa de Fraser, que toma o status coletivo como sua base, a distinção que Honneth faz em três esferas, cada qual com suas regras de relacionamento intersubjetivas baseadas em valores socialmente aceitos, dá ao indivíduo a possibilidade de criar expectativas sobre como deveria ser tratado individualizadamente. Não uma regra geral de igualdade, mas valores normativos pertinentes àquela esfera específica da vida social em sociedades pluralistas, com esferas de valor diversificadas. Isso possibilita ao grupo social, mas, sobretudo, ao indivíduo, que avalie em situaçóes bem concretas se e em que medida suas expectativas normativas legítimas 
estão sendo atendidas ou se estão sendo violadas e, portanto, se uma forma específica de injustiça lhe está sendo infringida. É isso que abre, na abordagem de Honneth, um amplo espectro de possibilidades para uma tomada mais imediata de consciência da injustiça e para uma motivação para a luta por reconhecimento por parte das pessoas diretamente afetadas - bem descritas pelo autor em suas reflexóes sobre a fenomenologia das experiências de injustiça social. E esta abordagem abre também novas possibilidades para a pesquisa empírica, permitindo que esta não fique na dependência da interpretação que movimentos sociais dão sobre sua situação e a motivação para suas mobilizaçóes.

No entanto, é fundamental que a teoria do reconhecimento não seja tomada de modo identitário pelas pesquisas empíricas. As vivências de desrespeito são as impulsionadoras privilegiadas das lutas por reconhecimento. Sendo assim, são essas vivências dos sujeitos investigados o ponto de partida da pesquisa empírica. E será a partir delas que melhor se poderá conhecer e compreender quais expectativas morais foram frustradas.

Conforme Honneth $(2007)^{9}$, até mesmo aqueles que não são capazes de articular uma noção positiva de justiça sentem quando são injustiçados. Neste ponto, a importância do movimento social é de se constituir em um espaço intersubjetivo onde a experiência individual de sofrimento é significada como uma experiência coletiva, de sujeitos que compartilham a mesma vivência - e que por meio de um processo de conscientização passa a ser significada como de sofrimento social, isto é, "[...] o sofrimento que é acompanhado pela violação das expectativas de membros para com a sociedade e que só podem ser cumpridas na sociedade" (SALONIA, 2008, p. 128-129). Daí o sentimento de injustiça ganhar um sentido de luta social, de luta por reconhecimento.

A teoria do reconhecimento, portanto, serve como lente para a análise das sociedades capitalistas modernas - ressalva feita pelo próprio autor em sua resposta a Fraser (HONNETH, 2006) - e náo como molde no qual conseguimos encaixar ou não a realidade observada. É profícuo tomar as esferas do reconhecimento enquanto um modelo (típico ideal) construído

9 Ver cap. 4. 
com o fim de servir de instrumento para o diagnóstico das diferentes expectativas morais - conforme cada área da vida - e das patologias sociais. $\mathrm{O}$ ponto arquimediano da teoria de Honneth, portanto, são os conflitos sociais - estes enquanto motivados por relaçóes frustradas de reconhecimento recíproco. Paulo Sérgio Neves (2005) tem mostrado isso tomando como referência a luta antirracista.

Não são válidas as críticas dirigidas a Honneth no sentido de atribuírem a ele a projeção de uma sociedade sem violações morais. Reconhecimento e desrespeito são noçóes indissociáveis na obra deste autor. Não é à toa que Honneth fala em formação da identidade "a mais intacta possível".

Retornando à pesquisa empírica, Salonia (2008) chama a atenção para o fato de que são objeto do pensamento crítico apenas aquelas formas de sofrimento "que são causadas por contextos sociais e, portanto, tendem para a sua alteração". Ou seja, a abordagem de Honneth abre simultaneamente espaço para maior autonomia do indivíduo (as, assim chamadas, autorrelaçóes práticas positivas) e da pesquisa social. Para ambos, abre-se um acesso mais imediato à interpretação de realidades sociais normativamente fundamentado.

Consideramos o primeiro texto de resposta de Honneth a Fraser um dos melhores textos para entender a teoria do reconhecimento. Destacaríamos nele dois aspectos: a fenomenologia das experiências de injustiça social e a questão dos critérios normativos para avaliar reivindicaçôes.

Em teoria social, a questáo da injustiça tem sido trabalhada como uma questão objetiva, como ocorre na teoria das classes, ou como o fator mobilizador de manifestaçóes ou movimentos sociais que reivindicam na esfera pública aquilo que consideram ser seu "direito". A abordagem de Honneth sobre a fenomenologia das experiências de injustiça social nos remete a um momento bem anterior: quando as pessoas afetadas percebem, com base nas suas expectativas justificadas pelos valores socialmente aceitos, que estão sendo injustiçadas. Bem antes de se formarem movimentos sociais, as pessoas, individualmente, já têm consciência de que são injustiçadas. Mais que isto: Honneth remete à questão da base normativa das reivindicaçôes de reconhecimento de "direitos". São direitos que estão sendo negados porque a sociedade aceitou para si como normativos certos valores, certas 
formas intersubjetivas de se relacionarem seus membros uns com os outros. Neste ponto, Honneth enriqueceu sua teoria ao assumir uma leitura da concepção de Marshall (1992) sobre cidadania, que coloca a comunidade como a fonte do conteúdo normativo que cada membro pode legitimamente esperar de sua condição de membro, de seu status de cidadão.

O segundo aspecto a ser destacado, que ficou mais bem formulado na primeira resposta de Honneth a Fraser, diz respeito à questão dos critérios normativos para avaliar reivindicaçóes. Muitas reivindicaçóes podem ser feitas, inclusive por movimentos sociais grandes e organizados. Mas, como ter critérios para julgar se uma reivindicação é justificada ou não? A própria questão de "valores majoritariamente aceitos" tem algumas limitaçôes; afinal, como se sabe amplamente, valores majoritariamente aceitos podem ser muito opressores. As experiências históricas com o nazismo e outros regimes autoritários levaram a que na Teoria Crítica haja uma forte reserva com relação a uma aceitação do critério de maiorias sociais de modo imediato como legitimador dos valores de uma comunidade.

O critério que Honneth coloca em discussão é o da promoção da emancipação: válidas seriam, segundo este critério, reivindicações que signifiquem um ganho em autonomia. Autonomia é compreendida, neste contexto, basicamente como poder elaborar e colocar em prática os próprios planos de vida. Esta capacidade está atrelada ao estabelecimento de autorrelações - autoconfiança, autorrespeito e autoestima - sadias, visto que a relação de alguém consigo próprio “[...] não é uma questão de um ego solitário refletindo sobre si mesmo, mas o resultado de um processo intersubjetivo contínuo, no qual sua atitude frente a si mesmo emerge em seu encontro com a atitude do outro frente a ele" (ANDERSON; HONNETH, 2011, p. 88, grifo do autor).

Duas formas básicas são descritas por Honneth como ganhos em autonomia em sociedade. De um lado, quando novos grupos sociais conquistam a possibilidade de elaborar e colocar em prática seus planos de vida. Pode-se exemplificar essa dimensão com a emancipaçãodas mulheres, com alguns aspectos de inclusão de negros e indígenas por intermédio de políticas públicas no Brasil. De outro, quando aspectos que antes eram socialmente controlados (ou reprimidos) podem ser decididos pelos próprios 
indivíduos. Há muito tempo a questão da profissão foi um âmbito destes: as famílias e os grupos sociais deixaram gradativamente de induzir os seus jovens a assumirem ocupaçôes sem muito respeito à vontade individual, libertando-os para a livre escolha profissional. Antes ainda foi a questáo da liberdade religiosa: tida historicamente como opção coletiva ou como forma de submissão ao governante de turno, passou a ser reconhecida como uma questão de consciência individual. Hoje algumas dimensôes da sexualidade estáo gradativamente sendo libertadas da heteronomia para fazer parte da esfera de autonomia das pessoas individualmente.

\section{Questões em perspectiva}

Depois deste debate em que fora "acusado" por Fraser de estar fazendo uma "psicologia moral" - e com releituras de Hegel e uma gradativa aproximação/paixão por Durkheim -, Honneth foi atrás de outras intuiçóes para preencher lacunas em sua teoria. Talvez a mais fundamental para sua teoria seja a importância das instituiçóes como o lugar onde os valores normativos da sociedade estão/estariam estabilizados. Em sua concepção, instituições teriam sido formadas justamente para serem o lugar social da realizaçáo duradoura de dimensóes valorativas fundamentais da respectiva comunidade.

Da mesma forma como valores majoritariamente aceitos podem ser opressivos, a estabilização de valores nas instituiçóes não corresponde, necessariamente, ao favorecimento de relaçóes de liberdade (social). Verificamos constantemente as instituiçóes protagonizando relaçóes de não reconhecimento ou de desrespeito, seja esta instituição a família ou o estado. Ao enfocar - demasiadamente - sua abordagem teórica nas instituiçóes, Honneth parece fechar um pouco a porta que havia aberto para a pesquisa empírica ancorada na teoria do reconhecimento, pois em $O$ direito da liberdade (2015) desprestigia relaçóes sociais e produção de sociabilidades que não passam pela mediação de instituiçóes (SOUZA, 2017).

Podemos extrair exemplos de relaçóes produtoras de autonomia que não passam por instituiçôes em diversos contextos: na rede de solidariedade das agricultoras na Guiné-Bissau responsáveis por toda a produção e reprodução da vida em um contexto muçulmano; as crianças que nas manifestaçóes de 2013 se constituíram como agentes políticos; os 
catadores de materiais recicláveis do Jardim Gramacho (Duque de Caxias/ $\mathrm{RJ})$ representados na arte de Vik Muniz; a militância das mulheres do MST pela agroecologia por se perceberem - individual e coletivamente como responsáveis pela geração e preservação da vida etc. ${ }^{10}$

Quando se alinha a Durkheim, Honneth parece aceitar o pressuposto de que as instituiçóes antecedem os indivíduos e as relaçóes sociais. Com isso, resgata o marco epistemológico da sociologia funcionalista, onde a sociedade e o indivíduo são entes separados, mediados pela primazia do todo sobre as partes. Esta questáo é antiga na sociologia. No campo da teoria crítica, porém, ela encontra em Habermas e sua teoria do agir comunicativo uma via para a sua superação; encontra também no próprio Honneth e em sua teoria do reconhecimento uma fundamentação para a convicção de que indivíduo e sociedade são indissociáveis. Além disso, Rahel Jaeggi (2014), com sua defesa de que a individualização e a socializaçáo seriam processos simultâneos, questiona aquela tese durkheimiana da primazia das instituições. Mesmo atentando para as instituiçôes como encarnação dos valores produzidos socialmente, esse novo enfoque de Honneth, explicitado em especial em $O$ direito da liberdade (2015), parece dificultar a percepção de como as instituiçóes são forjadas e tensionadas pelas lutas sociais, como ilustram alguns dos exemplos citados.

Nesse sentido, a teoria do reconhecimento nos parece, do ponto de vista sociológico, mais promissora por conceber indivíduos produzidos a partir de interaçóes sociais que são definidas por e produtoras de valores institucionalizados.

Entretanto, há duas questôes que não foram abordadas em profundidade neste debate de Fraser com Honneth - e que são cruciais para contextos em que nós vivemos e pesquisamos.

Primeiramente, a pergunta: de onde as pessoas aprendem aqueles valores que podem pressupor como legitimados em sua sociedade (e seu

10 As agricultoras da Guiné-Bissau foram entrevistadas por Elvira Gomes (ainda não publicado); a presença das crianças nas manifestações de 2013 em Porto Alegre/RS foi problematizada na dissertação de Porto (2017); as experiências dos catadores do Jardim Gramacho estão expressas no documentário "Lixo Extraordinário" (20 I0), dirigido por Lucy Walker e João Jardim; as mulheres do MST foram estudadas na dissertação de Santo (2016) e representadas no documentário "Terra para Rose" (1987), dirigido por Tetê Moraes. 
detalhamento e seu ancoramento institucional)? "Processos de aprendizagem” têm sido a expressão sob a qual, em escritos esparsos, esta questão foi discutida. Mas, ainda está longe de receber uma resposta satisfatória (SOBOTTKA, 2015). Novamente, há pistas empíricas que indicam a complexidade dessa questão, na medida em que o estado não pode ser tomado como a única fonte capaz de forjar o indivíduo enquanto conhecedor de seus direitos. Enfatizamos o potencial dos movimentos sociais frente à criação de condiçóes para o estabelecimento de laços intersubjetivos entre sujeitos e de conversão do que foi experienciado como negação em uma formulaçáo positiva, a projeção de uma vida melhor.

Nessa direção, Schütz (2004, p. 148) reconhece a centralidade dos movimentos sociais no processo de aprendizagem dos sujeitos enquanto cidadãos portadores de direitos na medida em que as experiências são constante e criticamente refletidas e, com isso, "[...] adquirem sentido emancipador, tornam-se força social [...]. O tornar-se consciente da experiência vivida é que supera o voluntarismo disperso e vulnerável". Para elucidar esta intuição, citamos uma liderança importante das mulheres do MST do Rio Grande do Sul, sobre as Comunidades Eclesiais de Base (CEBs). Ela conta que nasceu para os Sem Terra dentro da Igreja Católica: "A entidade minha era a Igreja, a reunião que nós se organizava pra ir pro Sem Terra era dentro da Igreja. Eu dou esse testemunho sempre, porque é um espaço também. A Igreja também é um espaço de formação" (SANTO, 2016, p. 66). Embora não haja uma resposta satisfatória para a questão de como os sujeitos aprendem os valores que podem pressupor como legitimados em sua sociedade, há evidências indicando que estes não são produto de um único meio de aprendizagem, especialmente em sociedades como a brasileira, onde o estado não é capaz de centralizar esta tarefa na medida em que constantemente viola direitos constitucionais básicos, como a educação, e, por outro lado, se faz presente nas periferias muito mais na forma de aparato policial repressor do que como prestador de serviços públicos constitucionalmente colocados como seu dever.

Um segundo desafio não tematizado é a questão: como lidar com situaçóes em que grandes contingentes de uma população ou grupo social que, devido à negação sistemática de reconhecimento nas diversas esferas, não conseguiu desenvolver autorrelaçóes práticas positivas sadias de forma 
adequada? Contextos, portanto, em que eles têm enormes limitaçóes em a) perceber a injustiça social a que estão submetidos; b) interpretar esta situação como sendo uma situação de negação do reconhecimento, de injustiça; c) encontrar formas simbólicas de articular percepção e interpretação em forma de um uso público da razão e d) incitar lutas sociais pelo reconhecimento, pela superação da injustiça, por meio de mobilizaçóes em movimentos sociais e de intervençôes na esfera pública.

Consideramos que o debate entre Fraser e Honneth trouxe avanços para a teoria social. Ele permitiu a explicitação de diversas facetas que estavam subteorizadas. De especial valor nos parece que, em meio a algumas questôes pontuais sobrevalorizadas, ambos também apontaram para a importância de um aprofundamento da dimensão empírica nos diagnósticos de época e revelaram como a fundamentação normativa da teoria social crítica continua sendo um desafio permanente. A verificação do potencial da teoria do reconhecimento para contextos específicos; no entanto, depende de que ela se torne ali uma teoria em ato.

\section{Referências}

ANDERSON, J.; HONNETH, A. Autonomia, vulnerabilidade, reconhecimento e justiça. Cadernos de Filosofia Alemã: Crítica e Modernidade, n. 17, p. 81-112, 2011.

ARMSTRONG, C.; THOMPSON, S. Parity of participation and the politics of status. European Journal of Political Theory, v. 8, n. 1, p. 109-122, 2009.

BRESSIANI, N. de A. Economia, cultura e normatividade: o debate de Nancy Fraser e Axel Honneth sobre redistribuição e reconhecimento. 2010. 151 f. Dissertaçáo (Mestrado em Filosofia) - Programa de Pós-Graduação em Filosofia, Universidade de São Paulo, São Paulo, 2010.

EISENSTADT, T. A. et al. (Org.). Latin America's multicultural movements: the struggle between communitarianism, autonomy, and human rights. New York: Oxford University Press, 2013.

FLICKINGER, H-G. Em nome da liberdade: elementos da crítica ao liberalismo contemporâneo. Porto Alegre: Edipucrs, 2003.

FRASER, N. Justice interruptus: critical reflections on the "postsocialist" condition. New York: Routledge, 1997.

FRASER, N. La justicia social en la era de la política de la identidad: redistribución, reconocimiento y participación. In: FRASER, N.; HONNETH, A. (Org.). ¿̨Redistribución o reconecimiento? Un debate político-filosófico. A Coruña: Paideia Galiza, 2006a. p. 17-88. 
FRASER, N. Una deformación que hace impossible el reconocimiento: réplica a Axel Honneth. In: FRASER, N.; HONNETH, A. (Org.). ¿̨edistribución o reconecimiento? Un debate políticofilosófico. A Coruña: Paideia Galiza, 2006b. p. 149-175.

FRASER, N. Reconhecimento sem ética? Lua Nova: Revista de Cultura e Política, n. 70, p. 101138, 2007.

FRASER, N; HONNETH, A. (Org.). ¿̨edistribution or recognition? A political-philosophal exchange. London: Verso, 2003.

FRASER, N.; HONNETH, A. ¿̨Redistribución o reconecimiento? Un debate político-filosófico. A Coruńa: Paideia Galiza, 2006.

HABERMAS, J. Theorie des kommunikativen Handelns I. Frankfurt am Main: Suhrkamp, 1988a. v. 1.

HABERMAS, J. Theorie des kommunikativen Handelns II. Frankfurt am Main: Suhrkamp, 1988b. v. 2.

HABERMAS, J. A luta por reconhecimento no estado democrático de direito. In: HABERMAS, J. A inclusáo do outro: estudos de teoria política. São Paulo: Loyola, 2002. p. 229-267.

HABERMAS, J. Arbeit und Interaktion. In: HABERMAS, J. Technik und Wissenschaft als "Ideologie". 18. ed. Frankfurt am Main: Suhrkamp, 2003. p. 9-47.

HONNETH, A. Kritik der Macht: Reflexionsstufen einer kritischen Gesellschaftstheorie. 3. ed. Frankfurt am Main: Suhrkamp, 2000.

HONNETH, A. Luta por reconhecimento: a gramática moral dos conflitos sociais. São Paulo: Editora 34, 2003.

HONNETH, A. Anerkennung als Ideologie. West End - Neue Zeitschrift für Sozialforschung, v. 1, n. 1, p. 51-70, 2004.

HONNETH, A. Redistribución como reconocimiento: respuesta a Nancy Fraser. In: FRASER, N.; HONNETH, A. (Org.). ¿Redistribución o reconecimiento? Un debate político-filosófico. A Coruña: Paideia Galiza, 2006. p. 89-148.

HONNETH, A. Disrespect: the normative foundations of critical theory. Cambridge: Polity Press, 2007.

HONNETH, A. O direito da liberdade. São Paulo: Martins Fontes, 2015.

JAEGGI, R. Kritik von Lebensformen. Berlin: Suhrkamp, 2014.

LUHMANN, N. Soziale Systeme: Grundriß einer allgemeinen Theorie. 6. ed. Frankfurt am Main: Suhrkamp, 1996.

MARCELO, G. Recognition and Critical Theory today: An interview with Axel Honneth. Philosophy \& Social Criticism, v. 39, n. 2, p. 209-221, fev. 2013. 
Reconhecimento, justiça e a questão da autonomia: desafios para uma teoria social normativa | Emil Albert Sobottka;

Thais Marques de Santo

MARSHALL, T. H. Citizenship and social class. In: MARSHALL, T. H.; BOTTOMORE, T. (Org.). Citizenship and social class. London: Pluto, 1992. p. 3-51.

MATTOS, P. O reconhecimento, entre a justiça e a identidade. Lua Nova: Revista de Cultura e Política, v. 63, p. 143-160, 2004.

NEVES, P. S. da C. Luta anti-racista: entre reconhecimento e redistribuição. Revista Brasileira de Ciências Sociais, v. 20, n. 59, p. 81-96, out. 2005. Disponível em: <http://www.scielo.br/scielo. php?script=sci_arttext $\&$ pid $=S 0102-69092005000300006 \& \operatorname{lng}=p t \& n r m=i s o \& t \operatorname{lng}=p t>$. Acesso em: 28 maio 2018.

PIERUCCI, A. F. Ciladas da diferença. Tempo Social, v. 2, n. 2, p. 7-33, 1990.

PINZANI, A. Jürgen Habermas. München: Beck, 2007.

PORTO, D. M. R. O princípio esperança e o movimento de multidáo de 2013. 2017. $97 \mathrm{f}$. Dissertação (Mestrado em Ciências Sociais) - Programa de Pós-Graduação em Ciências Sociais, Pontifícia Universidade Católica do Rio Grande do Sul, Porto Alegre, 2017.

RASCHKE, J. Sobre el concepto de movimiento social. Zona Abierta, n. 69, p. 121-134, 1994.

ROBEYNS, I. Is nancy fraser's critique of theories of distributive justice justified? Constellations, v. 10, n. 4 , p. $538-554,2003$.

SALONIA, M. Suffering from exclusion: on the critical impulse of the theory of recognition. Civitas, v. 8, n. 1, p. 125-136, 2008.

SANTO, T. M. de. As publicaçóes do setor de gênero do MST e as vivências das mulheres Sem Terra: reflexôes sobre desrespeito, reconhecimento e autonomia. 2016. 94 f. Dissertação (Mestrado em Ciências Sociais) - Programa de Pós-Graduação em Ciências Sociais, Pontifícia Universidade Católica do Rio Grande do Sul, Porto Alegre, 2016.

SANTOS, J. V. T dos; BARREIRA, C.; BAUMGARTEN, M. (Org.). Crise social e multiculturalismo: estudos de Sociologia para o século XXI. São Paulo: Hucitec, 2003.

SCHÜTZ, R. Potencialidades pedagógicas dos movimentos sociais populares. Civitas, v. 4, n. 1, p. 143-157, jan. 2004.

SOBOTTKA, E. A. A Escola de Frankfurt nos anos 1930. Sobre a teoria crítica de Max Horkheimer. In: Ribeiro, A. M. M.; SObOTTKA, E. A.; MUTZENBERG, R. (Org.). A modernidade como desafio teórico: ensaios sobre o pensamento social alemão. Porto Alegre: Edipucrs, 2008. p. 207-226.

SOBOTTKA, E. A. Recognition and learning process in modern societies. Justice and recognition: on Axel Honneth and critical theory. Prague: Filosofia, 2015. p. 89-104.

SOBOTTKA, E. A.; STRECK, D; R. When local participatory budgeting turns into a participatory system. Challenges of expanding a local democratic experience. International Journal of Action Research, n. 2, p. 156-183, 2014. 
SOUZA, L. G. da C. de. Do reconhecimento recíproco à sociedade efetivamente social: consideraçóes sobre a obra recente de Axel Honneth. Civitas, v. 17, n. 3, p. 98-114, 2017.

SOUZA, L. G. da C. de. Reconhecimento, redistribuição e as limitaçóes da Teoria Crítica contemporânea. 2013. 313 f. Tese (Doutorado em Sociologia) - Programa de Pós-Graduação em Sociologia, Universidade Estadual de Campinas, Campinas, 2013.

TAYLOR, C. A política do reconhecimento. In: TAYLOR, C. Argumentos filosóficos. São Paulo: Loyola, 1995. p. 241-274.

WEBER, M. Ensaios de sociologia. Tradução de Waltensir Dutra. 5. ed. Rio de Janeiro: Guanabara, 1982.

ZURN, C. F. Identity or Status? Struggles over Recognition. Struggles over Recognition in Fraser, Honneth, and Taylor. Constellations, v. 10, n. 4, p. 519-537, dec. 2003.

\section{Recognition, justice and the question of autonomy Challenges for a normative social theory}

\section{Abstract}

Scientific knowledge in general, and social theory in particular, progress with public debates. The debate that Nancy Fraser and Axel Honneth had two and a half decades ago contributed to better explain, in the context of Critical Theory, issues related to recognition, distributive justice, and also to the autonomy of individuals in a scenario in which new social movements and new themes contributed to diversify social struggles. This text briefly recalls the change in the scenario, delineate in large traces the emergence of Axel Honneth's proposal for a theory of recognition, to then addresses some of the key lessons learned in that debate, as well as points out contributions of Fraser to the field of Critical Theory. It concludes with a reflection on some implications of the debate that could become productive in our context.

Keywords: Recognition. Justice. Autonomy. Critical Theory.

Recebido em 01/10/2018

Aprovado em 15/11/2018 